Port Acadie

Revue interdisciplinaire en études acadiennes

An Interdisciplinary Review in Acadian Studies

\title{
Hommage au père Anselme Chiasson (1911-2004)
}

\section{Ronald Labelle}

Numéro 24-25-26, automne 2013, printemps-automne 2014

L'Apport des prêtres et des religieux au patrimoine des minorités : parcours comparés Bretagne/Canada français

URI : https://id.erudit.org/iderudit/1019120ar

DOI : https://doi.org/10.7202/1019120ar

Aller au sommaire du numéro

Éditeur(s)

Université Sainte-Anne

ISSN

1498-7651 (imprimé)

1916-7334 (numérique)

Découvrir la revue

Citer ce document

Labelle, R. (2013). Hommage au père Anselme Chiasson (1911-2004). Port

Acadie, (24-25-26), 17-19. https://doi.org/10.7202/1019120ar d'utilisation que vous pouvez consulter en ligne. 


\title{
Hommage au père Anselme Chiasson (1911-2004)
}

\author{
Ronald Labelle \\ CREMEA, Université de Moncton \\ Cape Breton University, Sydney
}

Pour ouvrir les journées d'étude sur les prêtres collecteurs, il est tout à fait approprié de s'arrêter au rôle joué par le père Anselme Chiasson. Né en janvier 1911, ce dernier aurait fêté ses 100 ans en janvier dernier, et, si la maladie ne l'avait pas emporté en 2004, je suis certain qu'il serait ici ce soir.

Le père Anselme a joué plusieurs rôles en Acadie : grand nationaliste, il a été un défenseur de la langue et de la culture, et il a agi ainsi sur plusieurs fronts. Par exemple, peu de gens savent que, dans les années 1970, il écrivait dans un journal des articles en acadjen qui dénonçaient des injustices envers les Acadiens et qu'il signait du pseudonyme « La Piquine ». En même temps, il était un représentant de l'Église et il a prêché l'importance de la foi toute sa vie, soit comme professeur de théologie morale ou prédicateur de nombreuses retraites.

Le père Anselme a largement fait la promotion des recherches historiques et il a été, entre autres, cofondateur de la Société historique acadienne au Nouveau-Brunswick en 1959. Il a aussi été un archiviste-c'est lui qui a bâti la collection du Centre d'études acadiennes de l'Université de Moncton -, en plus d'être un collecteur de traditions et l'auteur de nombreux ouvrages sur le folklore. Et cela sans compter l'important rôle qu'il a joué chez les Franco-Ontariens pendant une dizaine d'années avant son retour définitif en Acadie à la fin des années 1950. Voilà un autre aspect peu connu de sa vie. Si l'on ne présente pas son œuvre en détail au cours des prochains jours, c'est qu'on devrait tenir des journées d'étude centrées entièrement sur lui, tellement il a été engagé dans la société acadienne.

On a beaucoup rendu hommage au père Anselme : en 1981, à l'occasion de son $70^{\mathrm{e}}$ anniversaire, j'ai lancé le projet d'un recueil d'articles en son honneur qui a produit, avec la collaboration du professeur Lauraine Léger, les mélanges intitulés En r'montant la tradition (Éditions d'Acadie, 1982). Dans la section des hommages, Antonine Maillet écrivait : « De tous les Acadiens que je connaisse, le père Anselme Chiasson est le plus acadien ». Le père Anselme a reçu maintes décorations de son vivant qu'il 
serait trop long d'énumérer ici. Je mentionnerai seulement que le nouveau Centre des arts de son Chéticamp natal a été nommé en son honneur et que le Centre d'études acadiennes de l'Université de Moncton a été rebaptisé en 2007 Centre d'études acadiennes Anselme-Chiasson.

Quand le moment sera venu de faire le bilan de son œuvre, il faudra dépasser les simples hommages et analyser son œuvre d'une façon scientifique, car, en connaissant mieux le père Anselme, on acquerrait aussi une meilleure connaissance de la société acadienne dans son ensemble. Cela impliquerait bien sûr de porter un regard critique sur son œuvre. Une première étude de ce genre a déjà été menée par le père Godefroy Dévost, lui-même capucin, auteur de la biographie intitulée Les Deux Allégeances du père Anselme Chiasson (Centre d'études acadiennes, 2006). L'auteur a accompli un travail remarquable par ses recherches en archives et ses entretiens avec des gens de l'entourage du père Anselme. On y trouve un portrait très détaillé qui suit sa carrière depuis son départ pour les études en 1927 jusqu'à son décès survenu alors qu'il préparait une conférence pour le Congrès mondial acadien de 2004. L'auteur explique comment les cahiers de Chansons d'Acadie, parus à partir de 1942, ont fait découvrir la richesse de la culture populaire acadienne. Mais il aborde des questions délicates aussi, des questions qui nous font voir le père Anselme sous un autre angle. Le père Anselme a beaucoup été louangé pour les beaux recueils de Chansons d'Acadie qui ont fait connaître des bijoux du folklore acadien. En réalité, ils étaient tout autant l'œuvre de son cousin et collaborateur, le père Daniel Boudreau, qui était à la fois chanteur traditionnel et musicien. Le père Daniel est parti en mission aux Indes entre 1949 et 1967 ; pendant toutes ces années, aucun cahier de chansons n'est paru parce que c'était lui qui accomplissait l'essentiel du travail de compilation, en plus de transcrire les mélodies des chansons. Le père Daniel préférait toutefois rester dans l'ombre, alors que son collaborateur, le père Anselme, recevait les éloges.

Le père Anselme a beaucoup publié sur le folklore acadien. Tout comme les prêtres du début du $x^{e}$ siècle, comme Thaddée Bourque et Philéas Bourgeois, il possédait une vision un peu idéalisée du passé. En tant que maître de théologie, il prêchait l'attachement aux valeurs morales traditionnelles et son œuvre est nécessairement teintée par ses principes. On se rend compte, par exemple, que certaines des chansons folkloriques de Chéticamp ont été soit exclues des Chansons d'Acadie ou censurées avant leur publication.

On considère en général que le père Anselme a accumulé la collection la plus importante de folklore acadien, mais en réalité ses collectes dépassent peu les deux régions où il a concentré ses enquêtes, soit Chéticamp et les îles-de-la-Madeleine. Un examen approfondi de son 
œuvre de collecteur révélerait qu'une mission d'enquête entreprise à Rogersville, Nouveau-Brunswick, pour le compte du Musée national du Canada s'est rapidement terminée en échec. Le père Anselme a abandonné le projet, écrivant qu'il n'y avait pas à Rogersville un folklore qui vaille la peine d'être recueilli, alors que l'on sait aujourd'hui que cette région est riche en musique et en récits traditionnels. L'explication reste à trouver, mais l'on peut supposer que la culture locale qui existait à Rogersville ne correspondait pas à l'image de la vie traditionnelle que le père Anselme aurait aimé présenter.

Il y aurait bien des questions à poser au sujet de son œuvre et une étude minutieuse révélerait sans doute aussi des accomplissements positifs que l'on ne soupçonne pas encore. Je peux en citer ici un exemple : en préparant ma communication sur l'œuvre de sœur Catherine Jolicœur en tant que religieuse collectrice, j'ai découvert que le père Anselme Chiasson, directeur du CÉA en 1975, l'avait fait venir à Moncton et l'avait chargée d'étudier les légendes folkloriques acadiennes. Sœur Jolicœur venait de passer trois ans à compiler les légendes aux Archives de folklore de l'Université Laval, mais avait dû retourner enseigner dans les écoles des Maritimes à la fin de son contrat de travail. Le père Anselme a décidé qu'il fallait à tout prix soutenir les recherches de Catherine Jolicœur et il a réussi à l'accueillir temporairement au CÉA, ce qui lui a permis de se lancer dans sa grande collecte de légendes acadiennes. Finalement, si Catherine Jolicœur ne s'est pas laissé décourager après son départ de l'Université Laval, c'est probablement grâce à l'appui qu'elle reçut du père Anselme.

Le père Anselme est un personnage complexe. Il a peut-être été le plus acadien des Acadiens, comme l'a écrit Antonine Maillet, mais en même temps, son biographe, au terme d'une longue et patiente recherche, écrivait que le père Anselme " possédait une sensibilité qui n'était pas suffisamment soumise à la rationalité ». À bien y penser, c'était peut-être une bonne chose, car des considérations trop rationnelles auraient pu diminuer son enthousiasme pour l'Acadie et limiter son champ d'action. Pour l'avoir bien connu pendant une vingtaine d'années, je peux vous affirmer que rien ne l'arrêtait.

Enfin, je suis certain qu'une éventuelle analyse de la vie et de l'œuvre du père Anselme pourrait révéler des faits non seulement sur lui, mais aussi sur la communauté acadienne dans son ensemble, car il a été un personnage marquant de l'Acadie du $x^{e}{ }^{e}$ siècle. Voilà un beau sujet pour de futures journées d'étude. Il suffisait ici, dans cette cérémonie inaugurale d'un colloque international consacré à l'apport des prêtres et religieux au patrimoine des minorités, d'évoquer brièvement son action et de saluer sa mémoire. 